\title{
CICLOS ECONÔMICOS NA PRODUÇÃO, PREÇO E EXPORTAÇÃO DE CACAU NO BRASIL
}

\section{ECONOMIC CYCLES IN THE PRODUCTION, PRICE AND EXPORT OF COCOA IN BRAZIL}

\author{
Elaine Aparecida Fernandes* E-mail: eafernandes@ufv.br \\ *Universidade Federal de Viçosa (UFV), Viçosa, MG
}

Resumo: O presente trabalho buscou analisar, para a cultura cacaueira, a presença de ciclos econômicos na produção, exportação e preços dessa commodity. Através da análise espectral, observou-se a existência de comportamento cíclico em todas as séries. O ciclo bienal compartilhado por todas as variáveis refere-se ao ciclo vegetativo e reprodutivo da planta, ou seja, coincidentes com o cultivo e a maturação biológica do fruto. Os resultados mostraram ainda, um ciclo longo de 4,8 a 11,6 anos, que pode se referir ao efeito das variáveis exógenas na composição do preço internacional do cacau. Essas flutuações cíclicas elevam a instabilidade de preços, gerando desestímulo à produção em períodos de recessão e excedente em períodos de ascensão, resultando em flutuações nas quantidades exportadas.

Palavras-chave: Cacau. Análise Espectral. Ciclos. Brasil.

\begin{abstract}
This paper analyzes a presence of economic cycles in the production, export and prices of cocoa. Through spectral analysis, there may be a presence of cyclic behavior in all series. The biennial cycle shared by all as variables refers to the vegetative and reproductive cycle of the plant, that is, it coincides with the cultivation and biological maturation of the fruit. The results obtained, a long cycle of 4.8 to 11.6 years, can be consulted on the effect of exogenous variables on the composition of the international price of cocoa. These cyclical fluctuations increase price instability, creating a disincentive to production in periods of recession and exceeding rise estimates, resulting in fluctuations in exported quantities.
\end{abstract}

Keywords: Cacao. Spectral Analysis. Cycle. Brazil.

\section{INTRODUÇÃO}

O Brasil participa do comércio internacional exportando cacau em amêndoas desde 1961, mas, a partir de 1992, passou a ser também importador. Essa mudança deu-se, inicialmente, em decorrência da crise causada pela doença vassoura-debruxa, agravada posteriormente por fatores climáticos como, por exemplo, a seca. A queda na produção e os altos custos de manutenção diminuíram a área plantada, gerando déficits no abastecimento interno. Este fato fez com que o Brasil iniciasse a importação do produto de países como Gana e Costa do Marfim que vem se 
revezando na liderança da produção e exportação da commodity. Este contexto motivou a presente análise que buscou estudar as oscilações de preço, produção e exportação do produto para a economia brasileira. Este estudo é importante já que a indústria brasileira de chocolate ${ }^{1}$ vem crescendo consideravelmente nos últimos anos e exigindo, a cada momento, maiores quantidades de amêndoas. Para viabilizar essa maior produção de chocolate, a produção de cacau precisa se recuperar e ser mais eficiente internamente.

Em termos regionais, os estados do Pará e da Bahia respondem pela maior parte da produção, seguidos por pequenas produções nos estados de Rondônia, Espírito Santo, Minas Gerais (AIPC, 2020). Na Bahia, observa-se que o cultivo do cacau proporcionou o desenvolvimento das regiões do eixo llhéus - Itabuna e mesmo com o solo e produção afetados pela vassoura-de-bruxa, a região vem se modernizando e voltou a ter tendência ascendente em termos de valor exportado na década de 2000 e 2010. No Pará, Medicilândia, no oeste do estado e as margens da Transamazônica, se destaca em termos de solo fértil e, atualmente, o município possui 36 mil hectares de lavoura, sendo considerada a capital do cacau (IBGE, 2019). O chocolate produzido no Pará é um dos melhores do Brasil, pois tem um sabor específico dadas as características do solo.

Existem na literatura especializada estudos que versam sobre a existência de ciclos econômicos na produção, preço e exportação de commodities brasileiras. Pode-se citar os trabalhos de Martins e Martinelli (2010), Albuquerque e Moraes (2007), Monte e Amin (2013), Serigati e Possamai (2016), Amin (1994), Souza et al. (2013) e Miranda e Fernandes (2010).

Martins e Martinelli (2010), por exemplo, avaliaram a importância de se explorar o aspecto cíclico dos preços das commodities. Estudaram o açúcar procurando captar a dinâmica dos fatores de mercado que influenciam a formação do preço. Os autores concluíram que os indicadores antecedentes da commodity açúcar são um instrumento informativo para sinalizar o comportamento futuro do preço deste produto. Esta constatação possibilita a compreensão da natureza das flutuações dos preços e pode ajudar na formulação de estratégias de desenvolvimento.

\footnotetext{
${ }^{1}$ No final de 2019 e início de 2020, as fábricas de chocolate aumentaram cerca de $16 \%$ o volume de mão de obra empregada (ABICAB, 2020).
} 
Albuquerque e Moraes (2007) buscaram prever o preço médio mensal futuro do cacau, com base nos dados históricos de 1970 a 2005, através da metodologia Box-Jenkins. Os autores mostram que, apesar da modernização agrícola e dinamismo dos produtores, o preço possuí tendência de queda nos doze meses seguintes. Acrescentam também que a sazonalidade da colheita, que atinge seu patamar máximo em dezembro e o mínimo em julho, contribui para esse declínio.

Monte e Amin (2013) descreveram o comportamento do preço recebido pelos produtores, sua evolução e comercialização no período de 2003 a 2014. Apontam que, no curto prazo, há riscos persistentes no retorno do cacau, indicando que os choques da variância condicional levam algum tempo para desaparecer do mercado. Concluíram que as constantes flutuações de preços e volume de produção, no mercado à vista do cacau, são transportadas para o mercado de futuros atingindo as negociações do produto.

Serigati e Possamai (2016) apresentam a relação direta entre os ciclos de Kondratieff e os ciclos das commodities. Na fase de ascensão, têm-se que uma inovação tecnológica aquece a economia, que eleva a demanda. Os produtores levam tempo para responder ao choque na demanda, ou seja, somente quando a quantidade produzida pelos produtores aumenta, tem-se a elevação nos preços, e que, devido ao choque de demanda, desaceleram.

Amin (1994) mensurou a participação do agente especulador na formação dos preços de cacau. Entre suas contribuições, destacam-se as necessidades de ações conjuntas dos produtores, uma vez que ações individuais podem fazer o mercado mais confuso, mais instável e prejudicar economicamente o futuro de muitos produtores que nada têm a ver com as decisões governamentais.

Ao realizar a análise espectral e regras de filtragem, Souza et al. (2013) testaram a hipótese de eficiência semiforte de mercado (HEM) nos preços do contrato futuro de soja da BM\&F-Bovespa. Tem-se que, a HEM não se consolida em preços futuros da soja, identificando o potencial de arbitragem dos contratos, associado às características microeconômicas da indústria de soja no Brasil e, pelo processo de filtragem com diferentes valores de variação percentual, a ocorrência de estratégias operacionais lucrativas em determinados períodos. 
Por fim, tem-se o trabalho de Miranda e Fernandes (2010) que busca identificar a existência de ciclos econômicos para a commodity café, sendo base para o presente trabalho. Os autores identificaram a presença de ciclos de produção intrinsicamente ligados aos ciclos de exportação.

Como se pode perceber do conjunto de pesquisas mencionadas, tem-se listados trabalhos para outras commodities, exceto cacau, tornando o presente estudo pioneiro. Dessa maneira, para auxiliar na tomada de decisão dos produtores e órgãos governamentais, o presente estudo visa, de forma geral, analisar a existência de relação de longo prazo para as séries de produção, preço e exportação de cacau para e economia brasileira, entre os anos de 1900 a 2016. Especificamente, pretende-se identificar ciclos de preços, produção e quantidade exportada de cacau no Brasil; e determinar quais ciclos tem afetado, de forma mais significativa, o comportamento dos preços, quantidade produzida e exportação, identificando as suas respectivas magnitudes.

Para cumprir os objetivos propostos, o trabalho se estrutura em mais quatro seções além desta introdução. A próxima resume a teoria que define e explica o fenômeno dos ciclos econômicos. A terceira expõe a metodologia utilizada e a quarta detalha os resultados encontrados. Por fim, tem-se a última seção que mostra as principais conclusões obtidas pelo estudo.

\section{TEORIA DOS CICLOS ECONÔMICOS}

Os ciclos econômicos são conceituados como as flutuações recorrentes de longo prazo, ora expansiva, ora contrativa, da atividade econômica de um país, ou de um grupo de países, baseando-se na análise das oscilações das variáveis macroeconômicas.

O entendimento dos ciclos econômicos é ressaltado por Lima (2011, p. 1): "Entender as razões do movimento ondulatório das economias de mercado e procurar precaver-se contra ele é um dos principais desafios da pesquisa macroeconômica e da formulação de políticas de estabilização".

As teorizações acerca do tema deram-se, principalmente, no século $X X$, com a ocorrência de crises que afetaram as economias mundiais. Destacam-se os 
estudos de Kalecki, Kondratieff, Keynes e Schumpeter, que buscavam explicações e soluções para os ciclos recorrentes nas economias capitalistas.

A Teoria do Ciclo Econômico foi delineada por Kalecki (1933), com seu ensaio ‘Esboço de uma Teoria do Ciclo Econômico', e, posteriormente, aperfeiçoada em sua obra 'Teoria da dinâmica econômica: ensaio sobre as mudanças cíclicas e em longo prazo da economia capitalista', de 1954. Incialmente, adotou a hipótese dos ciclos puros, caracterizados pela ausência da linha de tendência, onde as flutuações da produção se dessem ao longo de uma linha horizontal não ascendente. Posteriormente, acrescentou a linha de tendência ascendente. Além disso, considerava a variação do investimento uma variável explicativa para as variações da economia. Através do seu efeito multiplicador, o investimento determinaria a demanda efetiva e a renda nacional. $E$, adicionada ao estoque de capital preexistente, ampliaria a capacidade produtiva, permitindo o crescimento econômico. Por fim, é essa variável que, com suas oscilações, gera os ciclos econômicos.

Kondratieff e Stopler (1935) mostram que os ciclos de longa duração no sistema capitalista resultavam de depreciações ou de investimentos em infraestrutura, como portos, canais, ferrovias etc. Em suas formulações, a Teoria do Investimento de Capital, a economia capitalista se desenvolve em ciclos de 50 anos. Os ciclos longos estão relacionados ao processo de efetivação tecnológica. $O$ investimento se daria em instalações preexistentes, a primeira fase, o que resultaria em um aumento da demanda, a priori. Terminada a primeira onda de investimentos, há uma saturação do mercado e sucateamento da instalação moderna, depreciando a produtividade marginal do capital e, desestimulando novos investimentos, gerando uma fase de estagnação econômica. A depreciação total dos recursos impulsionaria a criação de novíssimas técnicas que supririam o sucateamento dos capitais empregados na primeira fase.

$\mathrm{Na}$ visão de Schumpeter (1935), os processos cíclicos são divididos em quatro fases: prosperidade, recessão, depressão e renovação, que são utilizadas para datação e acompanhamento dos ciclos, onde a distinção entre fases é necessária para a apuração de quais 'forças' atuam em cada uma delas. Destacava que o cerne dos ciclos econômicos estava em sua causa, onde os fatores externos 
faziam-se importantes. Em sua teoria, o capitalismo teria por pilar o empresário investidor, onde o investimento torna-se uma causa exógena dos ciclos. O elemento motriz da evolução seria as inovações, que ao atingirem uma grande parte do mercado, provocariam desequilíbrios. Desse modo, pelo mecanismo dos ciclos, as fases de ascensão tendem a equilíbrios mais elevados, aumentando os lucros e a produtividade, recompensando o empresário inovador. Num segundo momento, com a absorção dessas inovações, segue-se o período de recessão, onde retrai-se o volume de investimento, reduzindo os novos níveis de emprego e renda que terminaria com a introdução de outra inovação, recomeçando as oscilações econômicas.

Burns e Mitchell (1946), por sua vez, buscam uma definição apropriada para o ciclo através da análise de 'ciclos específicos'. Para eles, o ciclo econômico não somente é uma flutuação na atividade econômica agregada, mas

[...] expansões que ocorrem ao mesmo tempo em diversas atividades econômicas, seguidas por recessões, contrações e recuperações igualmente generalizadas que se fundem com a fase de expansão do ciclo seguinte (BURNS; MITCHELL, 1946, p.3).

As análises macroeconômicas dos ciclos econômicos anteriores à Keynes eram baseadas em análises dinâmicas, buscando descrever as flutuações observadas. Na Teoria Geral, Keynes apresenta através de um modelo de características formais estáticas, buscando determinar o nível de produto agregado em torno do qual se dariam flutuações econômicas.

Em sua obra, Keynes discorre sobre a caracterização dos ciclos econômicos, como citado a seguir:

Sugiro, todavia, que o caráter essencial do ciclo econômico e, sobretudo, a regularidade de ocorrência e duração, que justificam a denominação ciclo, se devem principalmente ao modo como flutua a eficiência marginal do capital ... e ... Por movimento cíclico queremos dizer que, quando o sistema evolui, por exemplo, em direção ascendente, as forças que o impelem para cima adquirem inicialmente impulso e produzem efeitos cumulativos de maneira recíproca, mas perdem gradualmente a sua potência até que, em certo momento, tendem a ser substituídas pelas forças que operam em sentido oposto e que, por sua vez, adquirem também intensidade durante certo tempo e fortalecem-se mutuamente, até que, alcançado o máximo desenvolvimento, declinam e cedem lugar às forças contrárias. Todavia, por movimento cíclico não queremos dizer simplesmente que essas tendências ascendentes e descendentes, uma vez iniciadas, não persistam 
indefinidamente na mesma direção, mas que acabam por inverter-se. Queremos dizer, também, que existe certo grau reconhecível de regularidade na sequência e duração dos movimentos ascendentes e descendentes (KEYNES, (1996[1936]), p.293-4).

Dessa forma, o autor buscou identificar o princípio dos ciclos, buscando suas origens e causas, onde a natureza do ciclo é intrínseca ao capitalismo, que independente de choques, leva a uma economia cíclica, sempre em algum estágio do ciclo. Essa visão deu origem ao modelo de acelerador/multiplicador. O modelo baseia-se na natureza dual do investimento agregado, que é simultaneamente, pela teoria do multiplicador, um elemento determinante da demanda agregada, e pelo acelerador, criador de capacidade produtiva, gerando efeitos na oferta e efeitos na demanda.

Em contrapartida, as demais teorias relacionavam as flutuações da economia como resposta a choques. Em momentos de ausência, a economia estaria em um ponto de equilíbrio, ou em um intervalo de estabilização. Entretanto, com a ocorrência de choques, o efeito dissipador poderia atingir diversos níveis da economia, ocasionando flutuações ondulares.

\section{A CULTURA CACAUEIRA}

É fato que a história do cacau no Brasil está permeada por ciclos econômicos importantes de produção, preço e exportação. Para tentar solucionar as fases ruins desses ciclos, foi criada a Comissão Executiva do Plano da Lavoura Cacaueira (Ceplac) em 1957, por meio do Decreto 40.987. A sua principal função era recuperar as lavouras, aumentar e melhorar as condições de colheita e aspectos relacionados, além de criar meios para combater pragas e doenças.

A Ceplac proporcionou aumentos consideráveis na produção de cacau em anos posteriores à sua criação, colocando o Brasil, nas décadas de 1970 e 1980 como o maior produtor da cultura no mundo.

Nos anos de 2000, devido a vários fatores como estiagens, queda nos preços e aumento da doença vassoura-de-bruxa sobre as lavouras da Bahia, a produção voltou a diminuir e, dede então, vem oscilando consideravelmente. Atualmente, o 
Brasil é o sexto maior produtor de cacau no mundo, ficando atrás de Costa do Marfim, Gana, Indonésia, Nigéria e Camarões (AIPC, 2020).

Esta queda na produção foi acompanhada por um crescimento da indústria nacional de processamento das amêndoas e fabricação de chocolates, o que vem aumentando os níveis de importação do produto. Em 2018 e 2019, o Brasil importou 62,4 mil e 56,1 mil toneladas de amêndoas, respectivamente. Estas importações (99\%) vem principalmente de países da África como Costa do Marfim (AIPC, 2020).

O Brasil é o quinto no ranking dos países que lideram o volume de vendas de chocolate no varejo. O primeiro é os Estados Unidos, seguidos por Alemanha e Reino Unido. Em 2019, o faturamento do mercado de chocolates brasileiro foi de $\mathrm{R} \$$ 14 bilhões e as exportações desse mercado foram de 28 mil toneladas (ABICAB, 2019).

No que se refere às exportações de amêndoas, os seus volumes em 2018 e 2019 foram, respectivamente, de 616 e 491 toneladas. Em 2015, exportava-se 6,8 mil toneladas e depois desse ano, os montantes vem caindo sistematicamente. Entretanto, é importante observar que segundo a Ceplac (2020), os produtores vêm investindo em melhorias de qualidade nas etapas da cadeia, em especial no beneficiamento das amêndoas pós-colheita. Espera-se que, com isso, ocorra um aumento da produção e, consequentemente, das exportações brasileiras de cacau.

Em 2019, Japão e França foram os maiores compradores do cacau brasileiro. Neste ano, Pará, Bahia e Rondônia lideraram o ranking de exportação da commodity. O Pará exportou US\$1,24 milhão, enquanto a Bahia exportou, no mesmo período, apenas US\$ 616 mil (COMEX STAT, 2020). O Pará vem superando a Bahia, desde 2016, em termos de produção, exportação e sua produtividade, a cada momento, vem se destacando no cenário nacional e mundial.

No Pará, tem-se solos de média e alta fertilidade natural propícios ao cultivo do cacaueiro. Além disso, existe muitos produtores familiares interessados na produção cacaueira, fazendo com que o seu desempenho no estado seja positivo. Segundo o Censo Agropecuário de 2017 (IBGE, 2019), mais de 87\% dos estabelecimentos produtores de cacau são de agricultores familiares.

É importante ressaltar que a cultura do cacau, mesmo diante dos ciclos, vem conseguindo responder e aproveitar os desafios e oportunidades de crescimento. 
Segundo AIPC (2020), o setor emprega mais de 4.000 pessoas e é um dos elos de uma cadeia de mais de 120 mil pessoas, incluindo produtores rurais e indústrias de chocolate. Estima-se que, em termos de valor gerado, esse setor represente $R \$ 23$ bilhões anuais.

\section{METODOLOGIA}

\subsection{Raiz unitária}

As séries temporais são conjuntos de valores que uma variável apresenta ao longo de um determinado período. A característica da estacionariedade ${ }^{2}$ é requerida para que se possa generalizar seu comportamento ao longo do tempo, caso contrário, seu comportamento é restrito ao período escolhido. Entretanto, na maioria das vezes, as séries apresentam comportamento não estacionário em primeira diferença, sendo necessário a diferenciação ${ }^{3}$ em um número satisfatório de vezes para que essas séries se apresentem estacionárias.

Existem diversos testes que buscam analisar a presença da raiz unitária, no entanto, nesse trabalho foi utilizado o teste de Dickey e Fuller (1979), amplamente empregado na literatura econométrica por sua simplicidade e resultados satisfatórios para a detecção de problemas de não-estacionariedade de séries.

No modelo, "[...] a hipótese nula testada é que a série possui raiz unitária, ou seja, a série temporal é não estacionária, ou ela possui uma tendência estocástica, contra a hipótese alternativa que a série é estacionária" (GUJARATI, 2011, p. 749), deste modo:

$$
\begin{aligned}
& H_{0}: \delta=0 \\
& H_{1}: \delta<0
\end{aligned}
$$

Assim, considerando o seguinte modelo:

${ }^{2}$ Consideram-se séries temporais estacionárias aquelas em que a média, variância e autocovariância, em várias defasagens, permanecem constantes (GUJARATI, 2011)

${ }^{3}$ Referido como a ordem de integração das variáveis. 
$Y_{t}=\rho Y_{t-1}+u_{t}$

em que $Y_{t}$ é o valor da variável na atualidade, $Y_{t-1}$ é o valor defasado em um período dessa variável e $u_{t}$ é o termo de erro estocástico. Assim,

$\mathbf{E}\left(\mathbf{u}_{\mathrm{t}}\right)=\mathbf{0}$

$\mathbf{v}\left(\mathbf{u}_{\mathrm{r}}\right)=\sigma_{\mathrm{n}}^{2}$

$\operatorname{cov}\left(\mathbf{u}_{\mathrm{T}}, \mathbf{u}_{\mathrm{T}-\mathrm{K}}\right)=\mathbf{0}$; onde $\mathrm{T} \neq \mathrm{T}-\mathrm{K}$

Então, tem-se:

$$
\begin{aligned}
& Y_{T}-Y_{T-1}=\rho Y_{T-1}-Y_{t-1}+u_{t} \\
& \Delta Y_{t}=(\rho-1) Y_{t-1}+u_{t} \\
& \Delta Y_{t}=\delta Y_{t-1}+u_{t}
\end{aligned}
$$

Em que os valores tabulados para T (tau) derivam da simulação de Monte Carlo feito pelos autores.

\subsection{Análise espectral}

As séries temporais, conforme Santos et al. (2006), podem ser analisadas "tanto no domínio do tempo quanto no domínio da frequência, esta última tem sido utilizada na detecção e análise de ciclos nas séries econômicas" (p. 3). A técnica espectral, proveniente das ciências exatas, também é utilizada na economia e surgiu, de acordo com França (1990), como alternativa às técnicas de análises tradicionais, devido a sua capacidade de identificar comportamentos onde os métodos tradicionais são falhos, principalmente em séries temporais que possuem grandes sequências de observações. Em conformidade com França (2001), Russer e Cargil (1970) complementam que suas aplicações em séries econômicas visam medir a importância relativa de cada faixa de frequência em termos de suas contribuições para a variância total da série temporal. Isso é feito através de uma 
análise do espectro da série que é estimada usando-se a teoria da inferência estatística.

O conceito de análise espectral é sintetizado por Aguirre (1995) como "[...] a soma da análise estatística das séries temporais mais os métodos de análise de Fourier" (p. 41). O foco do método é a análise do espectro da autocovariância, que é definido como a transformada de Fourier ${ }^{4}$ da função de autocovariância.

O trabalho de França (1990) salienta que a técnica espectral decompõe uma série estacionária num conjunto de funções periódicas diferentes. Cada ciclo é caracterizado por sua frequência, amplitude e mudança de fase. O espectro de uma série $X_{i}$ se define como a contribuição da variância decomposta das séries em frequências diferentes.

Ao se considerar uma série econômica, cumprindo-se a característica de estacionariedade, deve-se atentar ao ponto de truncamento. Essa atenção se dá em virtude de sua determinação subjetiva, dado que não há consenso acerca de sua determinação na literatura.

Neste trabalho, utiliza-se o intervalo restrito $[0, \pi]$, pois quando se observa frequências maiores que $\pi$ ou períodos menores que duas vezes o intervalo das observações, ocorre o problema de Aliasing 5 . Ademais, alerta-se para a ocorrência do Leakage ou vazamento pelas bordas da janela de Parzen, onde o primeiro valor de y infla o primeiro valor da função de densidade de frequência.

Para a obtenção do espectro amostral contínuo, a partir de um conjunto finito de observações, tem-se que encontrar os estimadores de y(т) e, em seguida, de $f(w)$.

O estimador de $\mathrm{y}(\mathrm{T})$ é dado por:

$C(\tau)=\frac{1^{n-\tau}}{n_{t=1}} \Sigma\left(x_{t}-\bar{x}\right)\left(x_{t+\tau}-\bar{x}\right)$

em que $C(0)=s^{2}$

\footnotetext{
4 A essência da Transformada de Fourier de uma função cíclica é a decomposição ou separação dessa função numa soma de senóides de diferentes frequências.

5 O problema de aliasing pode existir em qualquer série de dados e ocorre em duas situações: na qual a taxa de amostragem é superior a capacidade de medição do sensor dado pelo tempo de resposta e o processo físico tem frequência maior do que a taxa de medida (MAGNAGO, FISCH e MORAES, 2010).
} 
Com isso, o estimador aparentemente adequado para o espectro é o periodograma, que é a permutação dos valores teóricos $\mathrm{y}(\mathrm{T})$ por valores estimados, expresso a seguir:

$$
I\left(w_{p}\right)=\frac{c_{0}+2 \sum_{\tau=1}^{n-1} c_{\tau} \cos w_{p} \tau}{\pi}
$$

Nota-se, entretanto, que apesar da obtenção do periodograma com a propriedade de ser um estimador assintoticamente não viciado da função de densidade espectral, a variância do periodograma não diminui, quando $\mathrm{N}$ aumenta. Dada essa constatação, apesar do periodograma ser uma forma natural de estimar a função de densidade espectral, ele proporciona um estimador pobre, requerendo algumas modificações.

Diante do exposto, para que $I\left(w_{p}\right)$ seja um estimador consistente de $f(w)$, é necessária uma suavização da função de autocovariância de modo a serem atribuídos pesos cada vez menores a defasagens cada vez maiores para eliminar o viés da variância.

Escolhidos o ponto de truncamento e a janela, podem-se encontrar os coeficientes de suavização $\lambda_{\mathrm{T}}$. Com isso, o estimador ideal de $f(w)$ pode ser obtido através da expressão 12.

$$
f(w)=\frac{1}{n}\left(\lambda_{0} c_{0}+2 \sum_{\tau=1}^{M} \lambda_{\tau} c_{\tau} \cos \tau w\right), 0 \leq w \leq \pi
$$

O teste de significância para o espectro estimado consiste em formular a hipótese nula, $\hat{f}(w) \leq \frac{\sigma^{2}}{\pi}$, indicando que todos os picos que ficarem acima dessa linha são significantes, enquanto aqueles que oscilarem abaixo, não são considerados significativos estatisticamente. 


\subsection{Fonte de dados}

Os dados utilizados para as quantidades produzidas e exportadas de cacau, e o valor da quantidade exportada se referem ao período de 1900 a 2016 . Os valores destas quantidades estão expressos em toneladas e os valores de exportação estão cotados em reais, deflacionados para o ano de 2016.

Para produção, utilizou-se os dados pertencentes ao Instituto Brasileiro de Geografia e Estatística, Pesquisa Agrícola Municipal (IBGE/PAM). Para exportação e preço, de 1900 - 1987, utilizou-se as Estatísticas históricas do Brasil: séries econômicas, demográficas e sociais; e, a partir de 1988, do Ministério do Desenvolvimento, Indústria e Comércio Exterior, Secretaria de Comércio Exterior (MDIC/Secex).

\section{RESULTADOS E DISCUSSÃO}

As séries temporais apresentam, em sua maioria, oscilações ao longo do tempo por serem afetadas por diversas variáveis (endógenas e exógenas). Estas séries podem conter também o componente de tendência. Para contornar este problema, o presente trabalho faz uso do teste de Dickey-Fuller Aumentado (1979). A Tabela 1 apresenta os valores críticos a $1 \%$ de significância e os valores calculados do teste para as variáveis selecionadas. Verificou-se que, em nível, as séries não são estacionárias, quando analisadas com intercepto e tendência, mas, analisadas em primeira diferença, não se observou a presença de raiz unitária.

Tabela 1 - Resultados do Teste Dickey Fuller Aumentado

\begin{tabular}{lll}
\hline \multicolumn{1}{c}{ Variável } & Valor Crítico a 1\% & Valor Calculado \\
\hline Produção & $-3,185792$ & $-4,039075$ \\
$\Delta$ (Produção) & $-13,71028$ & $-4,039797$ \\
Quantidade Exportada & $-4,040532$ & $-11,00724$ \\
$\Delta$ (Quantidade Exportada) & $-4,043609$ & $-8,476098$ \\
Preço & $-4,039075$ & $-2,668116$ \\
$\Delta$ (Preço) & $-4,043609$ & $-9,240319$ \\
\hline
\end{tabular}

Fonte: Resultados da pesquisa. 
A análise pelo espectro busca detectar a presença de ciclos através dos picos que ocorrem no periodograma, mas é válido enfatizar que ela não é capaz de explicar o fator gerador desses ciclos. Outro ponto importante é que para a mensuração correta do espectro, é imprescindível que as séries analisadas sejam estacionárias, e como pode ser notado na Tabela 1, isso ocorreu através da primeira diferença.

Para averiguar a significância dos ciclos estimados no periodograma, é construído o histograma do periodograma. Este teste fornece uma faixa de confiança superior, uma linha paralela dada pela distribuição exponencial, onde os ciclos significativos estão nas frequências com picos que se encontram acima dessa linha.

$\mathrm{Na}$ Figura 1, tem-se o periodograma da produção de cacau brasileiro no período selecionado.

Figura 1 - Espectro estimado para a produção de cacau no Brasil

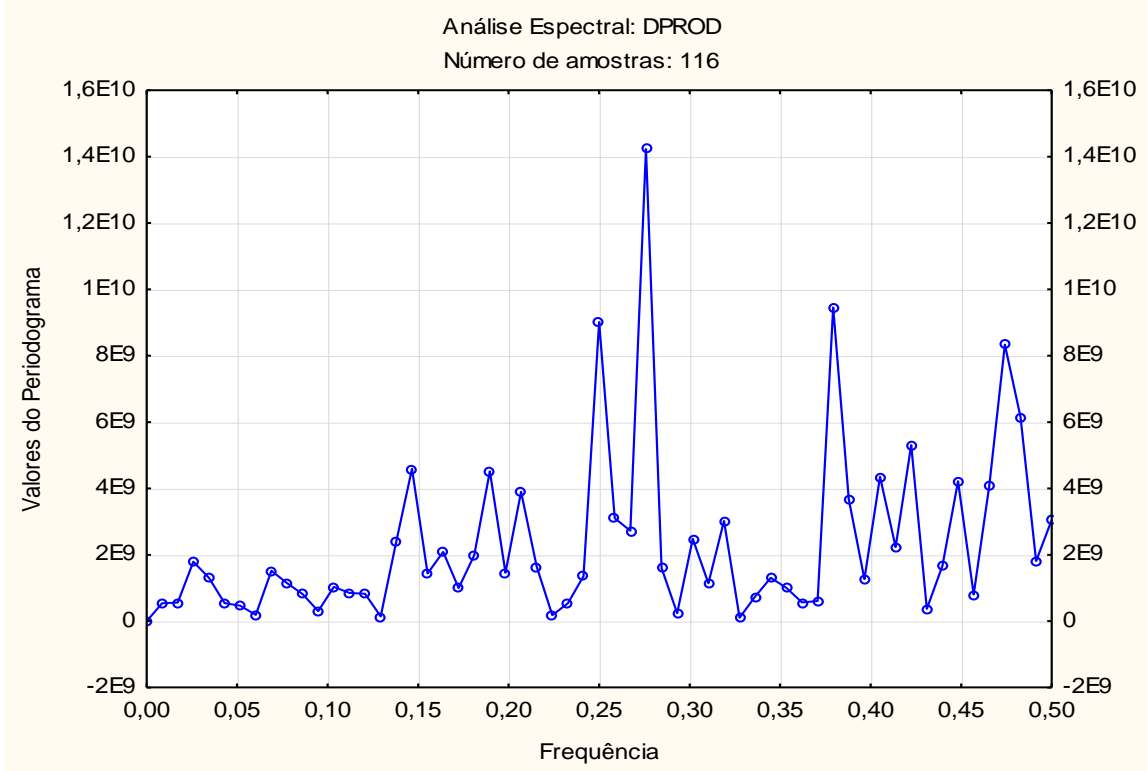

Fonte: Resultados da pesquisa.

Observa-se a existência de três intervalos de picos nas frequências, [0,14; $0,17]$, [0,23; 0,29] e [0,36; 0,49], que representam, respectivamente, os ciclos de 5,8 a 6,8 anos; 3,4 a 4,3 anos; e 2 a 2,8 anos. As significâncias dos ciclos podem ser verificadas na Figuras 2. 
Figura 2 - Histogramas do periodograma dos ciclos de longo prazo de produção (5,8 a 6,8 anos; de 4 a 4,3 anos, e 2 a 2,8 anos)
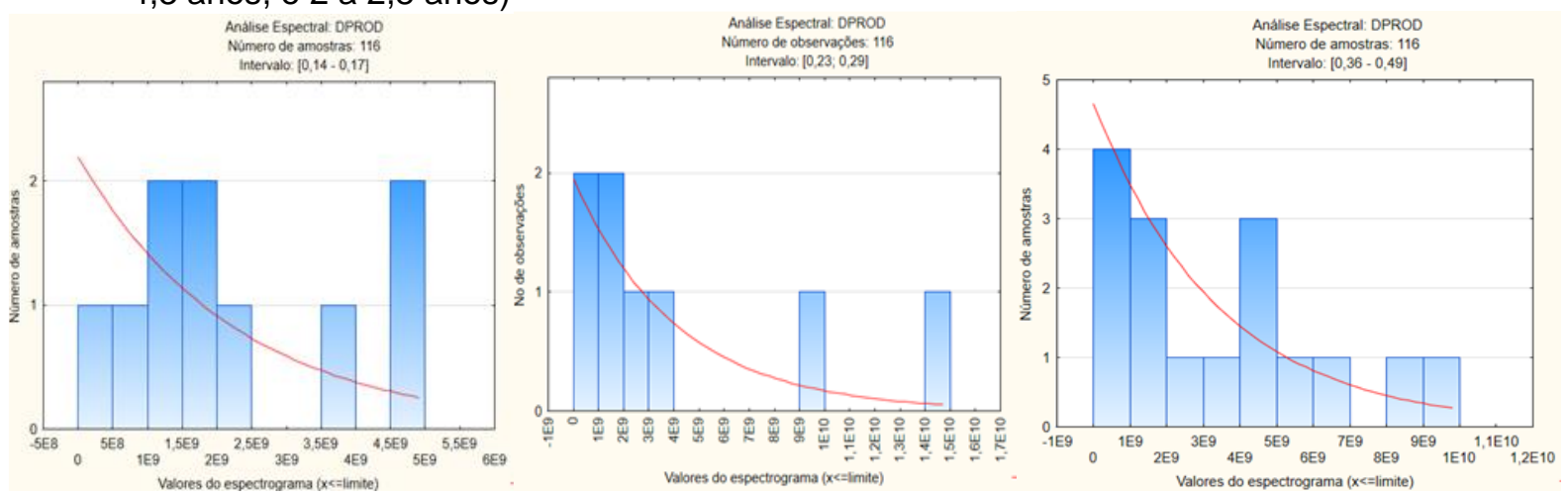

Fonte: Resultados da pesquisa.

Os resultados encontrados para a produção podem ser explicados pelo ciclo biológico do cacau. Desde o plantio a primeira colheita, é necessário o tempo de aproximadamente 2 anos. O período entre $\circ 2^{\circ}$ e $4^{\circ}$ ano é caracterizado por colheita dos frutos em todas as estações do ano e a partir do $5^{\circ}$ ano, tem-se a produção econômica do cacau, onde as colheitas são feitas em dois períodos: safra (novembro a fevereiro) e temporão (abril a agosto).

É importante ressaltar que o ciclo encontrado em torno de 7 anos pode estar relacionado com as oscilações advindas do declínio da cacauicultura baiana (estado responsável por $80 \%$ da produção brasileira) no final da década de 1980 . O fungo Moniliophtora perniciosa, que transmite a doença da vassoura-de-bruxa, afetou drasticamente a produção na região Ilhéus-Itabuna. Em 1991, a produção brasileira, que era de 320 mil toneladas por ano, diminuiu para 190 mil toneladas (FAPESP, 2017).

As décadas de 1990 e 2000 foram marcadas pelo combate epidemiológico e científico à vassoura-de-bruxa. O resultado foi o aumento da produção brasileira de cacau que atingiu, em 2014, 291 mil toneladas, a maior safra em 26 anos. Em 2015, a Bahia retoma suas exportações e vende 6,6 mil toneladas de amêndoas para o mercado europeu. (FAPESP, 2017)

Em 2016, entretanto, em decorrência da seca na Bahia e no Pará, a produção teve uma queda drástica, atingindo o menor nível desde 2005. Essa queda reduziu a área plantada, refletindo nas próximas colheitas do fruto. (BASTOS, 2018) 
A Figura 3 apresenta o periodograma para as quantidades exportadas do cacau brasileiro.

Figura 3 - Espectro estimado para a quantidade exportada de cacau no Brasil

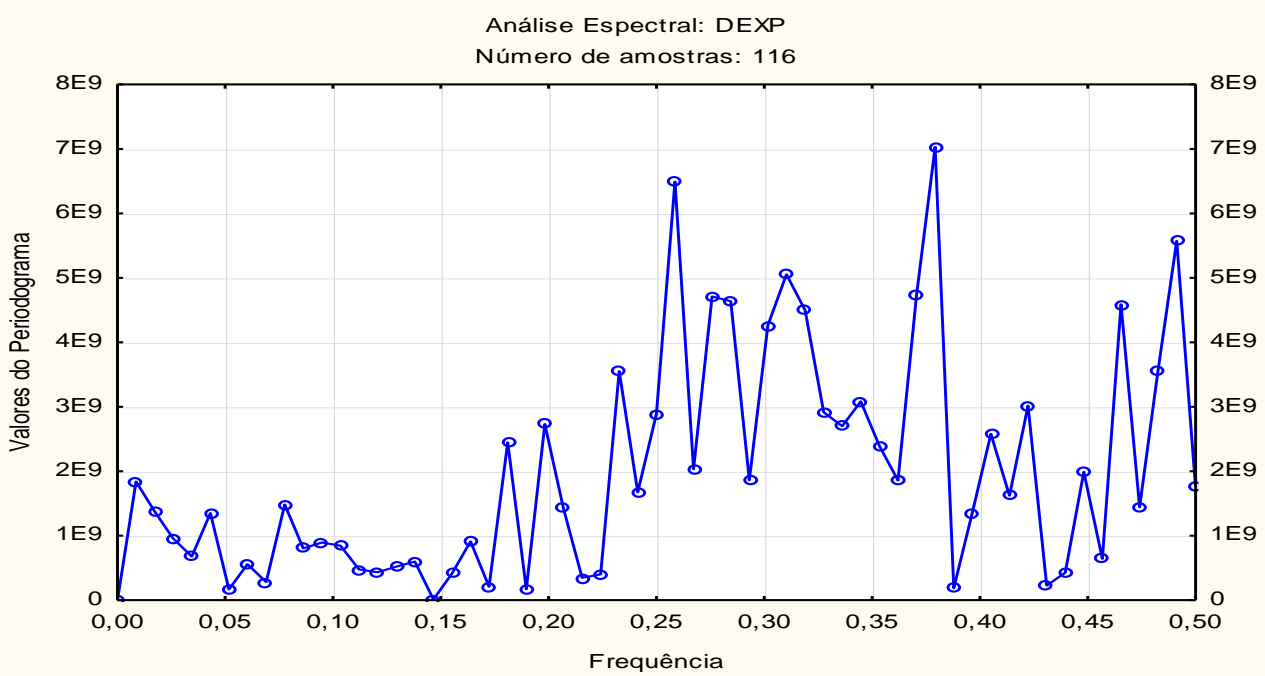

Fonte: Resultados da pesquisa.

O periodograma da quantidade exportada também apresentou três picos significativos. Os intervalos $[0,18 ; 0,26],[0,26 ; 0,38]$ e $[0,38 ; 0,50]$ representam ciclos de 3,7 a 5,5 anos, 2,5 a 3,7 anos e 2,0 a 2,5 anos, respectivamente. A Figura 4 ilustra a significância deste resultado.

Figura 4 - Histogramas do periodograma dos ciclos de 3,7 a 5,5 anos; 2,5 a 3,7 anos; e 2,0 a 2,5 anos, respectivamente
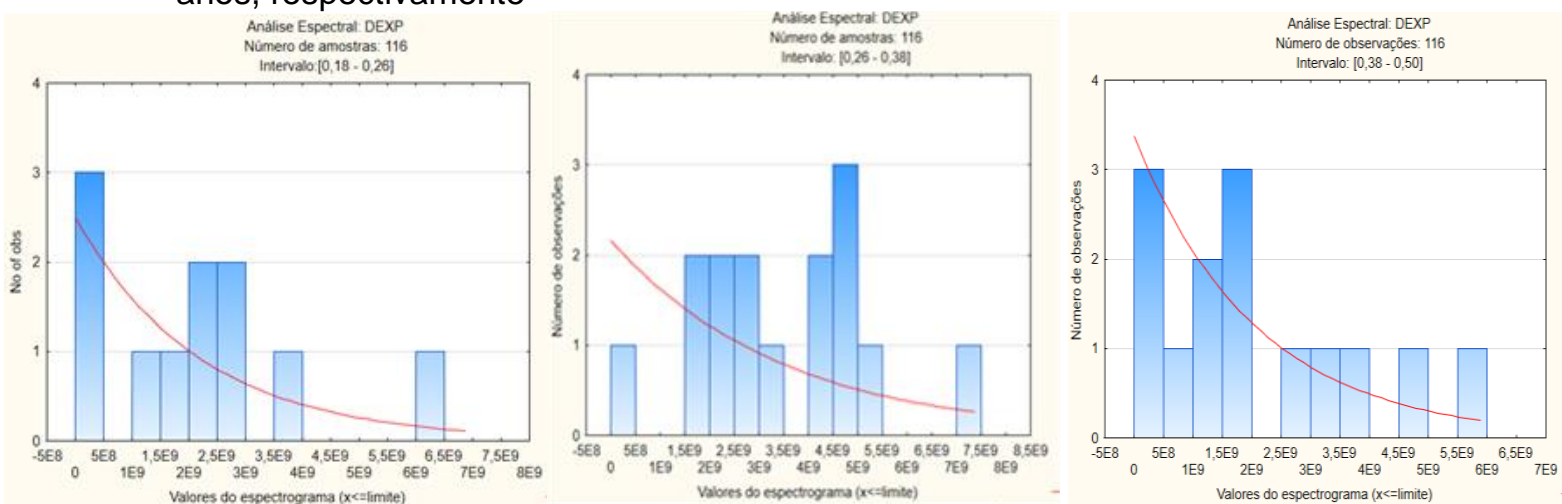

Fonte: Resultados da pesquisa.

Os ciclos identificados na quantidade exportada estão correlacionados aos encontrados na quantidade produzida. Em concordância com os estudos de Amin (1994) e, por apresentar uma demanda relativamente inelástica, e por possuir alta 
sensibilidade de preços, as oscilações dos preços afetam negativamente 0 consumo, e refletem nas exportações. Além disso, no caso particular do cacau, incidência de Moniliophtora perniciosa reduziu a quantidade e a qualidade da produção, encolhendo a participação brasileira no mercado internacional dessa commodity. Diante disso, têm-se a vinculação dos ciclos de produção (2,7 a 2 anos) e os ciclos de exportação (2,5 a 2 anos).

Por fim, tem-se o espectro estimado referente ao valor das exportações de cacau no período avaliado.

Figura 5 - Espectro estimado para o valor da exportação de cacau no Brasil

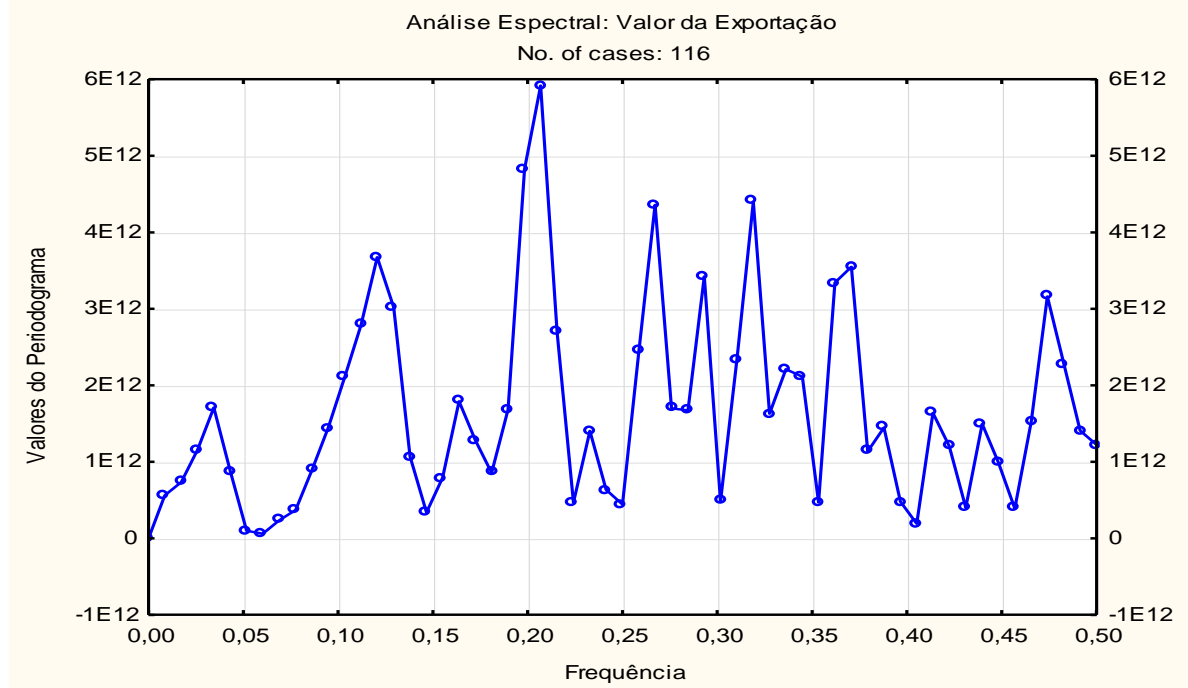

Fonte: Resultado da pesquisa.

Foram observados ciclos significativos nas frequências $[0,08 ; 0,22]$, $[0,23 ; 0,34]$ e $[0,37 ; 0,47]$, que equivalem, respectivamente, a intervalos de 4,8 anos a 11,6 anos; 2,9 a 4,2 anos; e 2,1 a 2,6 anos. A seguir, são apresentadas as significâncias dos períodos supracitados.

Acerca do preço das exportações, têm-se que suas oscilações são ações diretas das cotações no mercado internacional, valorizações cambiais e queda no diferencial de preço pago no mercado interno devido à importação realizada. Especificamente para o ciclo de 2,1 a 2,6 anos, observa-se que ele relaciona-se com as características biológicas da planta. 
Figura 6 - Histograma do periodograma do ciclo de 2,1 a 2,6 anos
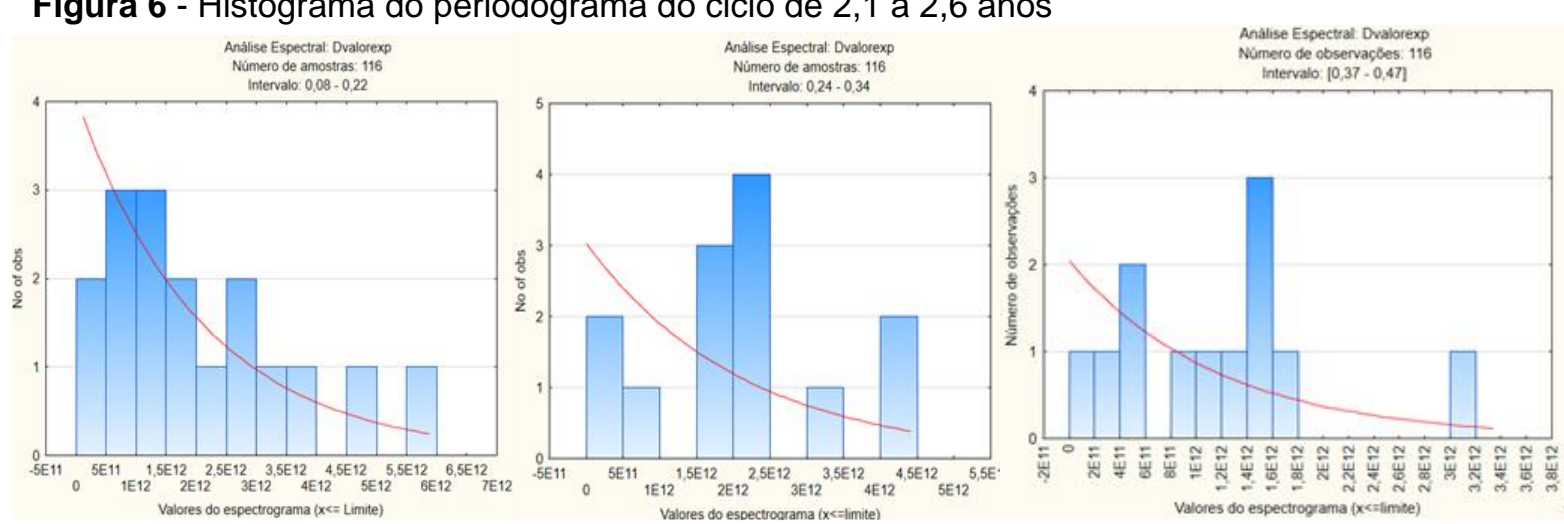

Fonte: Resultado da pesquisa.

O ciclo de 4,6 a 11 anos pode ser considerado um ciclo de Kondratieff, onde o período de boom corresponde a elevação dos preços externos, aquecendo a comercialização no mercado de commodities e consequente aumento de renda. Com a absorção do choque e, em paralelo, envelhecimento das plantas, ocorre a redução da produtividade e a diminuição da capacidade dos produtores brasileiros arcarem com os tratos adequados do manejo do cacau, observado na década de 1990 no Brasil. Esse declínio, seguido pela estagnação nos primeiros cinco anos da década de 2000, reverteu-se com a intensa participação da CEPLAC, que buscou alternativas menos onerosas no combate da vassoura-de-bruxa, elevando a produtividade do cacau brasileiro. Consequentemente, isso refletiu nas quantidades exportadas e no valor de sua exportação nos próximos anos.

Ademais, com a existência de correlação entre os ciclos de quantidade produzida e exportada, percebe-se que a renda decorrente das exportações absorve tanto o impacto interno da determinação de preços, quanto os fatores externos de flutuação.

\section{CONCLUSÃO}

O presente trabalho buscou analisar a existência de ciclos nas séries de produção, exportação e preços da cultura cacaueira no período de 1900 a 2016. Essa análise se faz importante diante das potencialidades do cacau brasileiro, principalmente o cacau amazônico, e o seu efeito no que tange as rendas advindas das commodities agrícolas brasileiras. 
Foram encontrados comportamentos cíclicos e componentes de tendência em todas as variáveis analisadas. Foram encontrados três ciclos significativos que mais contribuíram para a variância da série preço nas frequências $[0,08 ; 0,22],[0,23 ; 0,34]$ e [0,37;0,47], que equivalem aos ciclos de 4,8 a 11,6 anos; 2,9 a 4,2 anos e 2,1 a 2,6 anos. Para a variável produção, foram encontrados, também, três ciclos significativos, que correspondem: 5,8 a 6,8 anos; 3,4 a 4,3 anos; e 2 a 2,8 anos. A série de exportação apresentou três ciclos: 3,7 a 5,5 anos; 2,5 a 3,7 anos e 2,0 a 2,5 anos, respectivamente. $\mathrm{O}$ ciclo bienal compartilhado por todas as variáveis, refere-se ao o ciclo vegetativo e reprodutivo da planta, ou seja, convergentes com o cultivo a maturação biológica do fruto. O ciclo de preço captou ainda, um ciclo longo de 4,8 a 11,6 anos, que pode se referir ao impacto das variáveis exógenas na composição do preço internacional do cacau.

Essas flutuações cíclicas elevam a instabilidade de preços, gerando desestímulo à produção em períodos de recessão e excedente em períodos de ascensão, levando a flutuações nas quantidades exportadas.

Entender esses comportamentos cíclicos é imprescindível para entender o comportamento do mercado. Sendo assim, ações conjuntas entre governos e produtores - como as aplicados no programa Agricultura de Baixa Emissão de Carbono $(A B C)$, que visa o aumento de crédito de investimento para a implantação, melhoramento e manutenção de lavouras em sistemas florestais ou agroflorestais (MAPA, 2017) - vem reduzindo os impactos dessas oscilações, melhorando a produtividade e, por conseguinte, os resultados em termos de produção e exportação da commodity.

\section{REFERÊNCIAS}

ABICAB - Associação Brasileira da Indústria de Chocolates, Amendoim e Balas. Mercado 2019. Disponível em: http://www.abicab.org.br/. Acesso em: 17 abr. 2020.

AGUIRRE, A. Uma Introdução à Análise Espectral de Séries Temporais Econômicas. Nova Economia, Belo Horizonte, v.5, n. 1, p. 41-60, 1995.

AIPC - Associação Nacional das Indústrias Processadoras de Cacau. Importações de amêndoas, derivados e chocolates 2020. Disponível em: http://www.aipc.com.br/site/wpcontent/uploads/2020/04/Importa\%C3\%A7\%C3\%B5es-Gr\%C3\%A1ficos.pdf. Acesso em: 16 abr. 2020. 
AIPC - Associação Nacional das Indústrias Processadoras de Cacau. Exportações de amêndoas, derivados e chocolates 2020. Disponível em: http://www.aipc.com.br/site/wpcontent/uploads/2020/04/Exporta\%C3\%A7\%C3\%B5es-1.pdf. Acesso em: 16 abr. 2020.

ALBUQUERQUE, A. P.; MORAES, M. C. DE. Modelagem Econométrica para a Previsão do Preço Futuro do Cacau: Abordagem ARIMA. Revista Ciências Administrativas (UNIFOR), v.13, p. 193-207, 2007.

AMIN, M. Mário. A Influência da Atividade Especulativa na Determinação dos Preços Internacionais de Cacau no Mercado de Futuros de Nova lorque. Cadernos do Naea, Belém, PA., v. 12, p. 55-65, 1994.

BASTOS, Eduardo. Cacauicultura superar crise e retomar crescimento. Março, 2018. Disponível em: http://www.agroanalysis.com.br/index.php/3/2018/conteudoespecial/cacauicultura-superar-crise-e-retomar-crescimento. Acesso em: 03 nov. 2018.

BRASIL. Ministério da Agricultura, Pecuária e Abastecimento (MAPA), Secretaria de Desenvolvimento Agropecuário e Cooperativismo. Governo incentiva plantio de cacau com $\mathbf{R} \$ \mathbf{2 , 1 3}$ bilhões para investimentos. Brasília, 2017. Disponível em: http://www.agricultura.gov.br/noticias/governo-incentiva-plantio-de-cacau-com-r-2-13bilhoes-para-investimentos. Acesso em: 8 dez. 2019.

BURNS, A. F.; MITCHELL, W. C. Measuring business cycles. National Bureau of Economic Research. New York, 1946. 560 p.

COMEX STAT. Tabelas auxiliares. Disponível em: http://comexstat.mdic.gov.br/pt/home. Acesso em: 16 abr. 2020.

CONAB - COMPANHIA NACIONAL DE ABASTECIMENTO. Perspectivas para a agropecuária. 2014. Disponível em: file:///C:/Users/Usuario/Downloads/Perspectivas para a Agropecuaria - V.2 Safra 2014-2015.pdf. Acesso em: 16 abr. 2020.

DICKEY, D.A.; FULLER, W. Distribution of the estimators for autoregressive time series with unit root. Journal of the American Statistical Association, v. 74, n. 366, p. 427 - 431, 1979. https://doi.org/10.1080/01621459.1979.10482531

FAPESP. História genética do cacau no Brasil é descrita. Disponível em: http://agencia.fapesp.br/historia-genetica-do-cacau-no-brasil-e-descrita/24594q. Acesso em: 14 nov. 2018.

GUJARATI, D. N.; PORTER, D. C. Econometria básica. 5. ed. Porto Alegre: AMGH, 2011. $924 \mathrm{p}$.

IBGE. Censo Agropecuário Brasileiro 2017. Disponível em:

https://biblioteca.ibge.gov.br/index.php/biblioteca-catalogo?view=detalhes\&id=73096.

Acesso em: 17 abr. 2020.

IBGE. Estatísticas históricas do Brasil: séries econômicas, demográficas e sociais de 1550 a 1988. 2. ed. rev. e atual. Rio de Janeiro: IBGE, 1990.

KEYNES, J. M. A teoria geral do emprego, do juro e da moeda. São Paulo: Nova Cultural, [1936] 1996. 
KONDRATIEFF, N.; STOLPER, W. F. The long waves in economic life. The Review of Economic and Statistics, v. 17, n. 6, p. 105-115, 1935. https://doi.org/10.2307/1928486

LIMA, I. C. Ciclos Econômicos: teoria e evidência. In: ENCONTRO NACIONAL DE ECONOMIA, 39., 2011. [Anais...]. Foz do Iguaçu, 2011.

MAGNAGO, R.; FISCH, G.; MORAES, Osvaldo Luiz Leal de. Análise Espectral do Vento no Centro de Lançamento de Alcântara. Revista Brasileira de Meteorologia, v. 25, p. 260269, 2010. https://doi.org/10.1590/S0102-77862010000200010

MDIC, Dados do comércio exterior. Rio de Janeiro: Ministério do Desenvolvimento, da Indústria e Comércio Exterior. Disponível em: http://comexstat.mdic.gov.br/pt/geral. Acesso em: 24 nov. 2019.

MIRANDA, R. J. S.; FERNANDES, E. A.; SILVA, O. M. Ciclos de produção e preços na Cultura Cafeeira. Revista econômica do Nordeste, Fortaleza, v. 41, n. 1, p. 181-197, 2010.

MONTE, L. F. O.; AMIN, M. M. Análise da volatilidade do preço do cacau no mercado de futuros de Nova York (CSCE): Uma aplicação dos modelos GARCH. Contribuciones a La Economía, v. 8, p. 45-54, 2013.

ROSENBERG, N.; FRISCHTAK, C. Long waves and economic growth: a critical appraisal. American Economic Review, v. 73, n. 2, p. 146-151, 1983.

SANTOS, C. M.; LIMA, J. E.; LEAL, F.D.; BAPTISTA, A.J.M.S. Análise de ciclos na economia brasileira. In: CONGRESSO DA SOCIEDADE BRASILEIRA DE ECONOMIA E SOCIOLOGIA E RURAL, 44., 2006. [Anais...]. Fortaleza, CE, 2006.

SOUZA, W. A. R.; CARMO FILHO, M. M.; MARTINES-FILHO, J.G.; MARQUES, P. V. Uso de análise espectral e regras de filtragem em operações com contratos futuros de soja da BM\&F-BOVESPA. Revista de Administração Mackenzie, v. 14, p. 100-120, 2013. https://doi.org/10.1590/S1678-69712013000400007

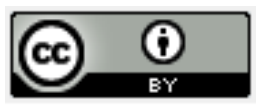

Artigo recebido 14/04/2019 e aceito para publicação em: 07/06/2020 DOI: http://dx.doi.org/10.14488/1676-1901.v20i2.4022 